\title{
Conditioning Play Audiometry
}

National Cancer Institute

\section{Source}

National Cancer Institute. Conditioning Play Audiometry. NCI Thesaurus. Code C85858.

An auditory test performed in children with hearing impairment. The child is asked to wait and listen for a specific stimulus. Subsequently, the child responds by performing a motor activity in response to the specific stimulus. 